\title{
Literature Review Study: Supporting and Inhibiting Factors of the Success to Stop Smoking
}

\author{
Ardhitya Sejati ${ }^{1 *}$, Sitti Nur Djanah ${ }^{2}$ \\ ${ }^{1}$ Postgraduate Public Health, Ahmad Dahlan University, Yogyakarta, Indonesia \\ ${ }^{2}$ Graduate Masters of Public Health Masters, Ahmad Dahlan University, Yogyakarta, Indonesia \\ *Corresponding author, Email: ardhisejati90@gmail.com
}

\begin{abstract}
Indonesia is the third country with the highest number of smokers in the world after China and India with a smoker's prevalence of $36.1 \%$. Many smokers have the desire to stop smoking but there are many obstacles to its success, so too the government has established a no-smoking area program (KTR). This study aims to review and compare several articles about inhibiting factors and supporters of the success of quitting smoking so that it becomes a public concern and a reference in making programs that support non-smoking areas (KTR). The design used was a literature review taken from the PubMed data base on inhibiting factors and supporters of successful smoking cessation. The articles that have been netted from PubMed are 50 articles and those that fit the inclusion criteria are qualitative research as many as 19 articles. Review literature research results described that the factors supporting the success of quitting smoking, namely 1) Individual factors (personal motivation, mindset, strong determination to stop smoking), 2) Regulations at work, 3) Social changes in the form of a non-smoking environment or region, 4) Having physical activity and social media can increase the success of quitting smoking. 5) When the intervention will be carried out, the intervention will be in the long term because the smoking tradition has strong roots. Things that can inhibit the success of quitting smoking are the main factors, namely 1) Social factors between smokers, both within the family and in the community, 2) Low knowledge and attitudes towards understanding about smoking and its dangers scientifically, 3) Problems in everyday life such as stress, financial problems, boredom and smoking habits when eating, 4) cigarette advertisements can encourage to continue smoking, 5) Difficulties in nicotine replacement. Things that can be concluded from the review literature that the success factors to stop smoking are determined by social factors, individual factors, and cigarette advertising, physical activity and workplace factors.
\end{abstract}

Keywords: success in quitting smoking, inhibitors of smoking success, literature review

\section{INTRODUCTION}

The behavior of community smokers is one of the health problems faced not only in Indonesia, but also in the world. Many efforts have been made to reduce the number of smokers ranging from anti-smoking campaigns, the application of high taxes, public service announcements about the dangers of smoking, and so on [1]. In ASEAN, the smoking policy is strengthened throughout the region in accordance with article 8 of the WHO FCTC. This smoke-free policy helps improve the health of workers and the general public by providing clean air for their health and well-being [2]. The health paradigm in overcoming the problem of tobacco has infiltrated the realm of policy both laws, government regulations, ministerial regulations to regulations at the regional level [3].
The prevalence of smoking in Indonesia is very high in various levels of society, especially in men ranging from children, adolescents and adults. The number of people who smoked in the past month in Indonesia in the last three years was around 23 percent, which means that about one in four Indonesians aged five years and over have smoked in the past month, whether smoking every day or smoking sometimes / not every day [1] .

The increasing prevalence of adolescent and adult smokers causes the problem of smoking to become more serious. Smoking behavior in the community does not occur without the things that encourage smokers to take action. Many factors encourage individuals to smoke. Broadly speaking, the factors that influence smoking behavior are environmental factors consisting of family and peer environment, and psychological satisfaction. 
Quitting smoking is not easy for cigarette addicts. One of the factors driving a person to stop smoking is a strong motivation in themselves. But in reality, many smokers who fail to stop smoking due to environmental factors.

This study aims to review and compare several articles about the factors that inhibit and support the success of quitting smoking so that it becomes a public concern and reference in making programs that support areas without smoking.

\section{METHOD}

The design of this study was literature review, researchers screened 50 literary studies from the PubMed database for review. The review literature method is adapted to the steps of the Systematic Literature Review, namely 1) Identification of problems, 2) Prioritizing problems and questions, 3) Creating a Framework, 4) Searching for literature, 5) Choosing articles, 6) Making critical assessments, 7) Extracting selected paper data, 8) Collecting data and making maps to answer questions.

Problem Identification: Based on background, problem identification that will be used as an article review is an article that states that there are supporting factors and obstacles to the success of quitting smoking so that it can become a public concern as a reference for creating programs that support non-smoking areas.

Research question: how does the comparison of the number of articles that indicate the presence or absence of supporting factors and inhibitors of the success of quitting smoking?

The framework in this review literature is to create a framework using the PEOS strategy, namely Population, Exposure, Results, and Study design. Literature search based on analyzing the comparison of the number of articles that show the presence or absence of supporting factors and inhibitors of the success of quitting smoking as follows:

Searching for articles in PubMed about the supporting factors and obstacles to success in quitting smoking totally 50 published articles

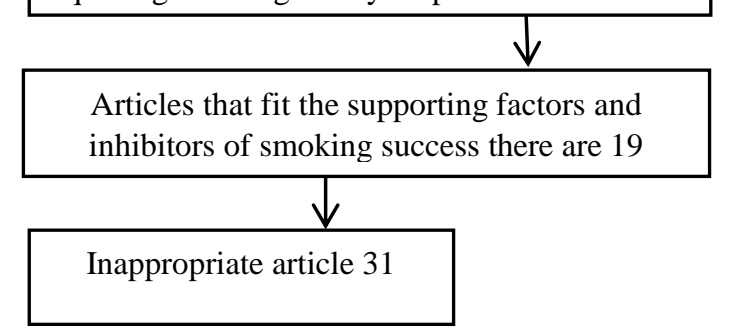

Thus, in the search for articles to compare the existence of supporting factors and factors that inhibit the success of quitting smoking, found as many as 50 articles, after filtering titles, abstracts, research methods found 19 articles to be taken and reviewed independently based on inclusion criteria, namely articles starting in 2015 -2019 and exclusion, i.e. inappropriate articles contained 31 articles. A total of 19 articles were filtered out that there were supporting and inhibiting factors for successful smoking cessation.

Mapping with a systematic search that obtained a description that research that describes the existence of supporting factors and inhibiting factors for successful smoking cessation, originated in the United States, Europe, China, and New Zealand.

\section{RESULTS AND DISCUSSION}

\section{Results}

1. Supporting factors for the success of quitting smoking Based on the results of a literature study from the PubMed database, a comparison of the factors that support the success of smoking cessation, found 11 articles, several articles that show the success of quitting smoking, namely:

a. Zou, Guanyang., (2019), titled "Factors influencing the implementation of a pilot smoking intervention for migrant workers in Chinese factories: a qualitative study" describes that supports the success of quitting smoking by providing group counseling and knowledge to stop smoking [4].

b. Granado-Font., (2018), with the research title "Coping Strategies and Social Support in a Mobile Phone Chat App Designed to Support Smoking Cessation: Qualitative Analysis" describes that supports the success of quitting smoking by establishing a smoke-free environment that is considered important for the success of quitting smoking and forming social support groups that are developed through applications to support emotional and provide information related to the dangers of smoking [5].

c. Brand (2018), with the research title "'Secretly, it's a competition': a qualitative study investigating what helped employees quit smoking during a workplace smoking cessation group training program with incentives" describes that supports the success of quitting smoking by personally motivating smokers to stop smoking and provide low income to workers who smoke in the workplace [6].

d. Lautner, C Shelby (2018), with the research title "Addressing the Needs of African American Male Smokers Through Community Outreach and Tailored Smoking Cessation Strategies" describes that supporting the success of quitting 
success to stop smoking, several articles that inhibit the success of quitting smoking, namely: smokers with a family approach to influence smoking cessation [7].

e. Griffen AK (2018), with the research title "Inclusion Wheel: Tool for Building Capacity and Public Health Leaders to Serve People With Disabilities" describes that health workers as the main motivators have a lot of social support to stop smoking and protect non-smokers from exposure to cigarette smoke [8].

f. Wells, Mary (2017), with the research title "Barriers and facilitators to smoking cessation in a cancer context: A qualitative study of patients, families and professionals" describes that some cancer patients who smoke have used smoking cessation services and have succeeded in quitting smoking. However, not all patients successfully stop smoking but there are still some patients who smoke after using smoking cessation services [9].

g. Smith (2017), titled the research "Revealing the complexity of quitting smoking: a qualitative grounded theory study of the natural history of quitting in Australian ex-smokers" describes that the process of quitting smoking on average through help and motivation to others to stop smoking [10].

h. Roberts (2017), entitled the study "Exercise to Support Indigenous Pregnant Women to Stop Smoking: Acceptability to Māori" describes that people in the Maori tribe (New Zealand) have a high level of physical activity to show that sports programs to help stop smoking [11]

i. Mena (2017), with the title of the research "The Influence of Engagement and Satisfaction on Smoking Cessation Interventions: A Qualitative Study" describes that to provide smoking cessation services, telephone counseling has the potential to reach large segments of the population with barriers to access and can cause behavioral changes to stop smoking [12].

j. $\quad$ King (2015), entitled the research "Evaluation of a newly developed tobacco program for people with disabilities" describes that social support can provide motivation to stop smoking, especially for people with disabilities [13].

k. Pledger (2015), with the research title "Exploring the experiences of pregnant women using an NHS stop smoking service: a qualitative study" describes that a pregnant smoker who has used NHS services to stop smoking, has obtained services such as motivation to stop smoking, risk health during pregnancy if you continue smoking, and get support and influence to stop smoking [14].

2. Factors Inhibiting the Success of Quitting Smoking

Based on the results of literature studies from the PubMed database, showing that there are factors that inhibit the success of smoking cessation, found 8 articles including articles on the factors driving a. Zou, Guanyang., (2019), with the research title "Factors influencing the implementation of a pilot smoking intervention among migrant workers in Chinese factories: a qualitative study" describes that in addition to supporting the research results there are also inhibiting factors namely social norms and traditions are the most important barrier to implementing stop smoking interventions is that smoking is seen as the most important communication tool and politeness in social life, a strong belief or determination to quit smoking is easy to relapse, and the relatively low socioeconomic status and education of migrant workers can also prevent success from quitting smoking [4].

b. Lautner, C Shelby (2018), with the research title "Addressing the Needs of African American Male Smokers Through Community Outreach and Tailored Smoking Cessation Strategies" describes that in addition to supporting the results of his research there are also inhibiting factors: a doctor who has provided information related to the dangers of smoking for health, but ignored and still to smoke, one of the hard parts to stop smoking is that there is a reminder to smoke again, the reason to keep smoking again is to relieve stress, eliminate boredom, economic problems, and environmental factors such as cigarette advertising on social media, cigarette advertisements in many corner shops in rural areas, and signs of danger on cigarette packets to keep smoking continuously [7].

c. Griffen AK (2018), with the research title "Inclusion Wheel: Tool for Building Capacity and Public Health Leaders to Serve People With Disabilities" explains that besides supporting the results of his research there are also inhibiting factors namely social pressure as the main reason for starting smoking [8].

d. P Pokhrel (2015), entitled the study "Young adult e-cigarette users' reasons for liking and not liking e-cigarettes: A qualitative study", outlines that hinders the success of quitting smoking that is currently e-cigarettes (vape) can serve expectations social and sensory characteristics that are unique compared to clove cigarettes so that ecigarettes are a substitute for tobacco. Use ecigarettes as a substitute for tobacco in order to stop smoking [15].

e. Heffner, Jaimee L (2018), with the research title "I Smoke Like This to Suppress These Issues that Are Flaws of My Character": Challenges and Facilitators of Cessation Among Smokers with Bipolar Disorder ", describes that social barriers, lack of awareness, avoidance of smokers, lack of knowledge about cigarettes and difficulty finding 
quitting smoking, clients will get knowledge and attitudes related to smoking. This smoking cessation counseling service is done by group counseling or by telephone. In counseling services, clients get support and encouragement so that the client has confidence in the ability to solve problems.

b. Motivation

The results of a literature review study, motivation is supportive of the success of quitting smoking. Personal motivation and mindset as the most important factors to stop smoking8. As one of the efforts to help smokers to quit smoking, information about smoking cessation is needed by instilling awareness and motivation of individuals, groups, and the community with a correct understanding of health that can encourage smoking cessation.

\section{c. Social Support}

The results of a literature review study, social support is supportive of the success of quitting smoking. This social support provides emotional support and information about smoking so that many smokers who successfully quit smoking. Social support psychologically helps smokers and their problems with the help of people around smokers. Families and couples have a very important role to help smokers to stop smoking.

d. Establishment of a No Smoking Area (KTR)

The results of a literature review study, the establishment of a no-smoking zone (KTR) is supportive of the success of quitting smoking. A non-smoking area (KTR) is a room or area that is declared prohibited for smoking or producing, selling, advertising, and / or promoting tobacco products19. Non-smoking area environment (KTR) is considered successful in reducing smokers because in each country and region already has regulations prohibiting smoking in offices, public places and in households.

\section{e. Physical Activity}

The results of a literature review study, physical activity is supporting the success of quitting smoking. Maori people (New Zealand) have a high level of physical activity which shows that an exercise program to help stop smoking [12]. The above research shows that exercise can reduce nicotine dependence on smokers. This is because regular exercise is able to prevent various effects of quitting smoking (nicotine withdrawal) that usually arises and destabilize the intention to smoke.

Based on the results of the literature review review, it can be discussed as follow:

1. Supporting factors for the success of quitting smoking a. Counseling

The results of a literature review study, counseling is supportive of the success of quitting smoking. By giving counseling about
2. Factors Inhibiting the Success of Quitting Smoking

a. Social Factors

The results of a literature review study, social factors are inhibiting the success of quitting smoking. Social tradition is the most important 
communication tool [5]. Social pressure is the main reason for starting smoking [9]. This is because smoking is a culture in developing countries and in some developed countries. Besides culture, the large number of smokers is also influenced by the increasingly diverse cigarette advertisements.

b. Information From Health Personnel

The results of a literature review study, information from health professionals is hampering the success of quitting smoking. A smoker has been given information about the dangers of smoking by health workers. But in reality, it was ignored by a smoker because a smoker has not been able to release the effects of nicotine that appears on him.

c. Use of E-Cigarettes

The results of a literature review study, the use of e-cigarettes is inhibiting the success of quitting smoking. The reason smokers use ecigarettes is as a substitute for smoking to stop smoking. As a result, many smokers turn to ecigarettes because they believe they can avoid them from the risk of heart disease and cancer associated with using tobacco cigarettes. Ecigarettes work by heating the liquid that is in the tube and then produces steam like smoke which generally contains various chemicals.

\section{CONCLUSION}

1. Many scientific articles have outlined the factors of success in quitting smoking and inhibiting the success of quitting smoking.

2. Supporting factors for successful smoking cessation are individual factors (personal motivation, mindset, strong determination to stop smoking), regulations at work, social changes in the form of a non-smoking environment or area, having physical activity and social media can increase the success of quitting smoking, when will carried out interventions, and these interventions in the long term because the tradition of smoking is strongly rooted.

3. Inhibiting the success of quitting smoking is a social factor between smokers, both within the family and in the community, knowledge and attitudes are still low on understanding about smoking and its dangers scientifically, problems in daily life such as stress, financial problems, boredom and smoking habits when eating, cigarette advertisements can encourage smoking to continue, and difficulties in nicotine replacement.

\section{SUGGESTIONS}

It is recommended to relevant agencies to provide socialization in the community as well as in workplace agencies based on inhibiting factors and supporting the success of quitting smoking as a reference in the formation of a no-smoking area (KTR).

\section{REFERENCES}

[1] Badan Pusat Statistik, 2018, Profil Kesehatan Ibu dan Anak, Badan Pusat Statistik: Jakarta

[2] Lian, Tan Yen, 2016, The Tobacco Control Atlas Asean, South Asia Tobacco Control Alliance: Thailand

[3] [3]. Wibisono, Nauran, dkk, 2014, Kretek Kemandirian dan Kedaulatan Bangsa Indonesia, Koalisi Nasional Penyelamat Kretek

[4] Zou, Guanyang, et all, 2019, Factors influencing the implementation of a pilot smoking cessation intervention among migrant workers in Chinese factories: a qualitative study, BMC Public Health. 2019; 19: 870. BioMed Central Public Health

[5] Granado-Font, et all, 2018, Coping Strategies and Social Support in a Mobile Phone Chat App Designed to Support Smoking Cessation: Qualitative Analysis, JMIR Mhealth Uhealth. 2018 Dec 20;6(12):e11071

[6] Brand, Floor A Van den, et all,2018, 'Secretly, it's a competition': a qualitative study investigating what helped employees quit smoking during a workplace smoking cessation group training programme with incentives, BMJ Open. 2018; 8(11): e023917

[7] Lautner, C Shelby, et all, 2018, Addressing the Needs of African American Male Smokers Through Community Outreach and Tailored Smoking Cessation Strategies, Am J Mens Health. 2018 Nov; 12(6): 2055-2063

[8] Griffen AK, et all, 2018, Inclusion Wheel: Tool for Building Capacity and Public Health Leaders to Serve People With Disabilities, Health Promot Pract

[9] Wells, Mary, et all, 2017, Barriers and facilitators to smoking cessation in a cancer context: qualitative study of patient, family and professional views, BMC Cancer (2017) 17:348

[10] Smith, et all, 2017, Revealing the complexity of quitting smoking: a qualitative grounded theory study of the natural history of quitting in Australian ex-smokers, Tob Control. 2018 Sep;27(5):568-576 
This to Suppress These Issues that Are Flaws of

[11] Roberts, et all, 2017, Exercise to Support Indigenous Pregnant Women to Stop Smoking: Acceptability to Māori, Matern Child Health J. 2017 Nov;21(11):2040-2051

[12] Mena, et all, 2017, The Influence of Engagement and Satisfaction on Smoking Cessation Interventions: A Qualitative Study, Subst Use Misuse. 2017 Feb 23;52(3):322-331

[13] King, et all, 2015, Evaluation of a newly developed tobacco cessation program for people with disabilities, Disabil Health J. 2016 Jan;9(1):145-9

[14] Pledger, 2015, Exploring the experiences of pregnant women using an NHS stop smoking service: a qualitative study, Perspect Public Health

[15] P Pokhrel, et all, 2015, Young adult e-cigarette users' reasons for liking and not liking ecigarettes: A qualitative study, Psychol Health. 2015 December ; 30(12): 1450-1469

[16] Heffner, Jaimee L, et all, 2018, “I Smoke Like
My Character": Challenges and Facilitators of Cessation Among Smokers with Bipolar Disorder, Division of Public Health Sciences, Fred Hutchinson Cancer

[17] Research Center, Seattle, WA USA J Dual Diagn. 2018 ; 14(1): 32-39

[18] Rossem, Carolien Van, 2015, Smoking cessation in primary care: Exploration of barriers and solutions in current daily practice from the perspective of smokers and healthcare professionals, European Journal of General Practice, 2015; Early Online: 1-7

[19] Mena, et all, 2015, Smoking cessation; engagement; health coaching; qualitative interviews; satisfaction, J Cancer Surviv. 2016 Apr;10(2):312-9

[20] PP Nomor 109 Tahun 2012 Tentang Pengamanan Bahan Yang Mengandung Zat Adiktif Berupa Produk Tembakau Bagi Kesehatan 